\title{
Novel Antidepressants in the Pipeline (Phase II and III): A Systematic Review of the US Clinical Trials Registry
}

\section{()(1) $\odot \Theta$}

Authors

Hitoshi Sakurai ${ }^{*}$, Kengo Yonezawa2, ${ }^{*}$, Hideaki Tani², Masaru Mimura², Michael Bauer4, Hiroyuki Uchida²

\section{Affiliations}

1 Department of Neuropsychiatry, Kyorin University School of Medicine, Tokyo, Japan

2 Department of Neuropsychiatry, Keio University School of Medicine, Tokyo, Japan

3 Department of Neuropsychiatry, Kawasaki Municipal Hospital, Kanagawa, Japan

4 Department of Psychiatry and Psychotherapy, Technische Universität Dresden, Dresden, Germany

Key words

antidepressant, depression, fast-acting, pipeline, treatmentresistant depression

received 27.08 .2021

revised 08.10 .2021

accepted 12.11.2021

published online 19.01 .2022

\section{Bibliography}

Pharmacopsychiatry 2022; 55: 193-202

DOI 10.1055/a-1714-9097

ISSN 0176-3679

(c) 2022. The Author(s).

This is an open access article published by Thieme under the terms of the Creative Commons Attribution-NonDerivative-NonCommercial-License, permitting copying and reproduction so long as the original work is given appropriate credit. Contents may not be used for commecial purposes, or adapted, remixed, transformed or built upon. (https://creativecommons. org/licenses/by-nc-nd/4.0/)

Georg Thieme Verlag KG, Rüdigerstraße 14,

70469 Stuttgart, Germany

\section{Correspondence}

Hiroyuki Uchida, MD, PhD

Department of Neuropsychiatry

Keio University

School of Medicine

35 Shinanomachi

Shinjuku-ku

160-8582 Tokyo

Japan

hiroyuki_uchida@keio.jp

\section{ABSTRACT}

Introduction There is an imminent need for faster-acting and more effective antidepressants beyond the monoaminergic hypothesis.

Methods We systematically searched the US Clinical Trials registry for antidepressant compounds with completed phase II and III trials. Compounds that demonstrated significant superiority over placebo in the primary outcome measure in the latest phase of phase II and III trials were identified. The collateral information was gathered via a PubMed search and press releases.

Results Nine compounds were identified. AXS-05 (a combination of dextromethorphan and bupropion) and ansofaxine hydrochloride showed a positive result over placebo in a phase III study for major depressive disorder or treatment-resistant depression. MIJ821, nitrous oxide, psilocybin, ayahuasca, facial injection of botulinum toxin $\mathrm{A}$, prasterone, and casopitant demonstrated at least one positive result in phase II trials. Ayahuasca showed a greater response rate than placebo at week one, indicating the rapid antidepressant effect.

Discussion These new compounds with novel mechanisms of action are expected to provide a greater variety of treatment options for depression if preliminary positive results are confirmed.

\footnotetext{
These authors contributed equally to this work.
} 


\section{Introduction}

Antidepressants based on the monoamine hypothesis of depression have played a crucial role in treating major depressive disorder (MDD) for decades [1]. Current treatment guidelines recommend the use of selective serotonin reuptake inhibitors (SSRIs) and serotonin-norepinephrine reuptake inhibitors (SNRIs) for initial treatment [2-4]. However, there are several challenges associated with the use of these antidepressants. First, the onset of antidepressant action is delayed; numerous double-blind, randomized controlled trials (DBRCTs) have demonstrated that the superiority of antidepressants to placebo generally occurs two or more weeks after initiating the intervention [5]. Second, approximately one-third of the patients with MDD do not achieve remission even after up to four antidepressant trials [6]. Furthermore, $40 \%-70 \%$ of those who initially responded to the treatment subsequently relapse within 1 year [7]. These shortcomings of conventional antidepressants emphasize the imminent need for faster-acting and more effective antidepressants beyond the monoaminergic hypothesis.

While SSRIs and SNRIs are still called "newer" antidepressants, the first SSRI, fluoxetine, was introduced to the market more than 40 years ago; much newer promising antidepressant compounds have recently been tested [8-10]. For example, multiple studies have demonstrated the effectiveness of ketamine, an N-methyl-Daspartate receptor (NMDAR) antagonist, and (s)-ketamine, an Senantiomer of ketamine, for treatment-resistant depression (TRD) and suicidal ideation $[11,12]$. Furthermore, there are several rapid-acting antidepressant compounds, such as $\alpha$-amino-3-hydroxy5-methyl-4-isoxazole propionic acid receptor (AMPAR) modulators, metabotropic glutamate receptor antagonists, $\gamma$-aminobutyric acid type A receptor modulators, muscarinic receptor antagonists, and psychedelic drugs [8-10]. However, despite their promising preliminary results, some of these compounds failed to show any significant benefit over placebo in phase II and III trials.

In this review, we conducted a systematic search of the US Clinical Trials registry for antidepressant compounds in the pipeline and reviewed the compounds that showed positive results in the most recent phase of phase II and III trials.

\section{Methods}

We performed a systematic search for DBRCTs of antidepressant compounds in the US Clinical Trials registry (https://clinicaltrials. gov/), with the following filters: condition or disease, "depression"; recruitment, "completed" or "unknown"; and trial phase, "Phase II" and "Phase III" (last search: August 22nd, 2021). The trials were excluded if (1) they recruited patients with bipolar depression, depression due to physical or neurological disorders, or premenstrual dysphoric disorder; (2) compounds tested were already marketed for depression; (3) compounds tested as adjunctive therapy to ongoing antidepressants; (4) depressive symptomatology was not assessed as a primary outcome. After identifying clinical trials that fulfilled the selection criteria, test compounds that demonstrated statistically significant superiority over placebo in the primary outcome measure at the primary endpoint in the latest phase were identified. Collateral information on the included compounds was gathered from published articles via a PubMed literature search and press releases. The compounds were excluded from this review if the literature search revealed that they failed to obtain approval for depression or their development was terminated. TRD was defined as depression that failed to respond to one or more antidepressant trials in the present review. The superiority to placebo was defined as significant effectiveness over placebo in the primary outcome measure at the primary endpoint. Response was defined as $a \geq 50 \%$ score reduction at primary endpoint from baseline in the Montgomery-Asberg Depression Rating Scale (MADRS), 17-item or 21-item Hamilton Depression Rating Scale $\left(\mathrm{HAMD}_{17}\right.$ or $\left.\mathrm{HAMD}_{21}\right)$, or 16-item Quick Inventory of Depressive Symptomatology SelfReport (QIDS-SR ${ }_{16}$ ). Rapid-acting was defined as demonstrating superiority to placebo in response rate by the end of the first week of treatment.

\section{Results}

The search schematic is shown in - Fig. 1. A total of 176 antidepressant compounds were assessed for eligibility, and 167 compounds were excluded based on the exclusion criteria and negative study results. Thus, nine compounds fulfilled all selection criteria ( $\triangleright$ Table 1). The compounds which were excluded due to a lack of any significant positive result or termination of development are summarized in $>$ Table 2.

\section{AXS-05}

AXS-05 is a combination of dextromethorphan, a non-selective NMDAR antagonist, and bupropion. Bupropion is compounded to protect dextromethorphan from being rapidly metabolized via cytochrome P450 2D6 and provides antidepressant effects. AXS-05 (45 mg dextromethorphan and $105 \mathrm{mg}$ bupropion twice daily) demonstrated significant improvement in the MADRS total score reduction of 16.6 compared to 11.9 for placebo at week 6 (primary outcome) in one phase III DBRCT of 327 patients with TRD $(p=0.002)$ (NCT04019704) [13]. A significant reduction in the MARDS total score was also observed at week 1 compared to placebo $(p=0.007)$. While the response rate of AXS- 05 at week 6 was different from that of placebo $(54.0 \%$ versus $34.0 \%, p<0.001$ ), there were no data at any other time points. While the most commonly reported adverse events in the AXS-05 group were dizziness, nausea, headache, diarrhea, somnolence, and dry mouth, their incidence rates were not reported. There was no information on dissociative symptoms, psychotic symptoms, or dependence. In another phase III DBRCT of 312 patients with TRD (NCT02741791), they were randomized to treatment with either AXS-05 $(45 \mathrm{mg}$ dextromethorphan and $105 \mathrm{mg}$ bupropion) or $150 \mathrm{mg}$ bupropion, twice daily for 6 weeks [14]. In this study, the antidepressant effect of AXS-05 was shown with significant MADRS total score reductions of 5.2 for AXS- 05 versus 3.6 for bupropion at week $1(p=0.02)$ and 8.0 for AXS-05 versus 6.1 for bupropion at week $2(p=0.035)$. In contrast, there was no significant superiority in the MADRS score reduction at week 6 (primary outcome, 11.6 for AXS-05 versus 9.4 for bupropion, $p=0.117$ ) [14]. The response rates at these time points were not reported. The most commonly reported adverse events in AXS-05 were dizziness and nausea without any information on their frequency, while dissociative symptoms, psychotic symptoms, or dependence were not reported. One phase III openlabel safety trial for 876 participants has been completed without 


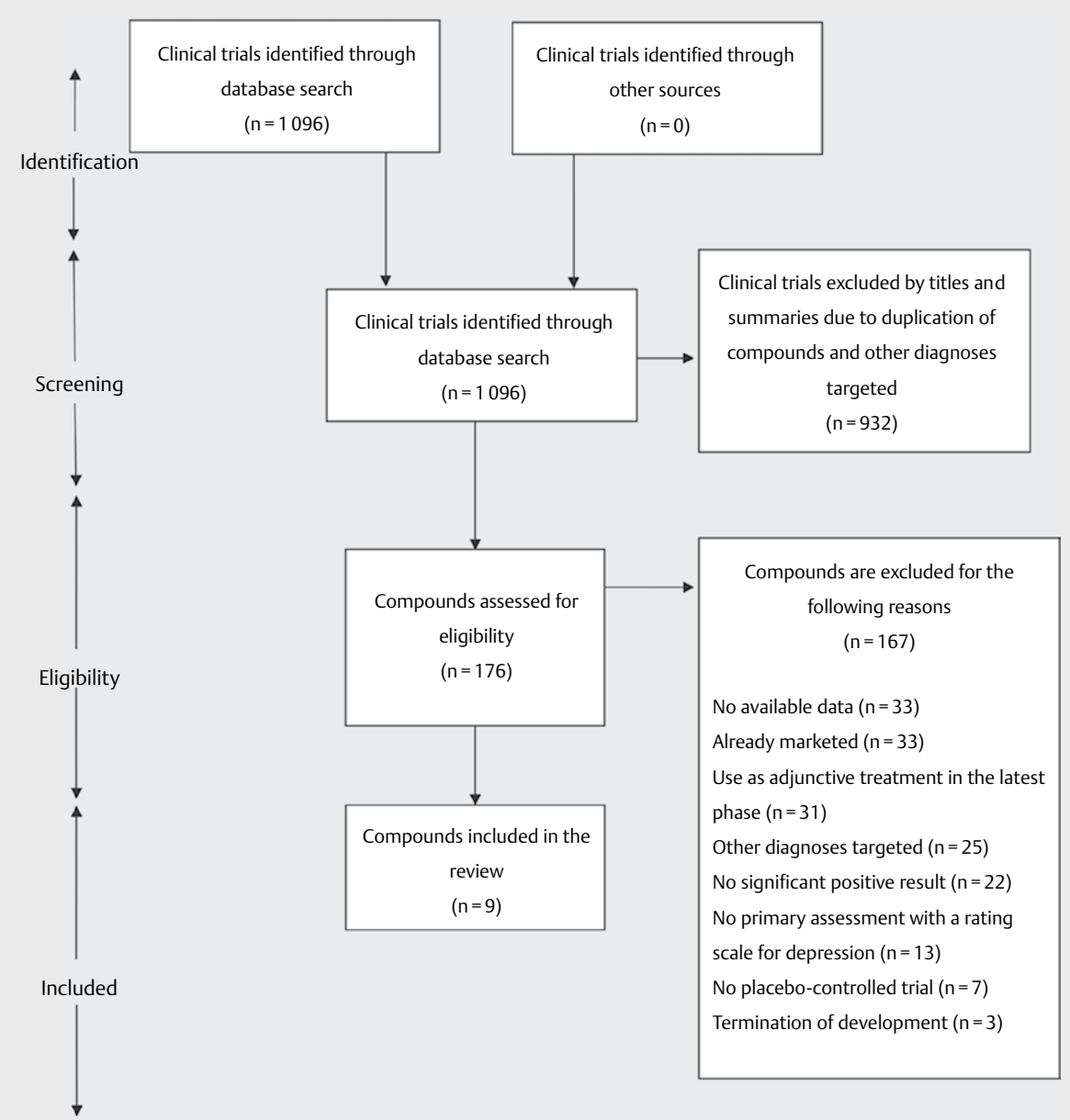

- Fig. 1 A flow diagram of search of clinical trials and antidepressant compounds.

any reported results (NCT04039022). In a recent phase II study for 44 patients with TRD in stable remission, AXS-05 twice daily significantly delayed the time to relapse up to 52 weeks as compared to placebo (primary outcome, $p=0.002$ ) (NCT04608396) [15]. There were no treatment-emergent adverse events reported in more than one patient in the AXS-05 group. The U.S. Food and Drug Administration granted fast track designation for TRD and breakthrough therapy designation for MDD to AXS-05 [14]. One phase II trial was still in the recruitment stage on ClinicalTrials.gov (NCT04634669) as of August 22, 2021.

\section{MIJ821}

MIJ821 (CAD9271) is an NMDAR subtype 2B negative allosteric modulator. In a phase II DBRCT of 70 patients with TRD, MIJ821 at doses of $0.16 \mathrm{mg} / \mathrm{kg}$ and $0.32 \mathrm{mg} / \mathrm{kg}$ was administered via infusion on a weekly or bi-weekly basis for 6 weeks and compared with $0.5 \mathrm{mg} / \mathrm{kg}$ of ketamine and placebo administered weekly (i.e. 6 arms in total) (NCT03756129) [16]. There were greater reductions in the MADRS total score at 24 hours (primary outcome) in the pooled MIJ821 $0.16 \mathrm{mg} / \mathrm{kg}$ group $(-15.51, \mathrm{p}=0.0013)$ and the pooled MIJ821 $0.32 \mathrm{mg} / \mathrm{kg}$ group $(-12.98, \mathrm{p}=0.0196)$ than placebo group (-7.27). While the intravenous ketamine group demon- strated a score reduction of -12.9 in the MADRS, no comparison was made to MIJ821 or placebo. The significant antidepressant effects of MIJ821 were also observed at 48 hours but not 6 weeks. Response rate according to the MADRS was not reported in this study. The most frequent adverse event in MIJ821 was amnesia (10.0\%). Dissociation was observed with an incidence rate of $5.0 \%$ in the pooled MIJ821 group. One phase II trial in patients with MDD who have suicidal ideation with intent was still in the recruitment stage on ClinicalTrials.gov (NCT04722666) as of August 22, 2021.

\section{Nitrous oxide}

Nitrous oxide is an inhalational anesthetic commonly used in dentistry, emergency centers, and ambulatory surgery centers [17] and acts as an NMDAR antagonist. In a phase II crossover DBRCT of 20 patients with TRD, 1 -hour inhalation of $50 \%$ nitrous oxide plus $50 \%$ oxygen was superior to that of placebo gas in the improvement of the $\mathrm{HAMD}_{21}$ at 2 hours $(-4.8$ versus $-2.3, \mathrm{p}<0.001)$ and 24 hours (primary endpoint, -5.5 versus $-2.8, p<0.001$ ) (NCT02139540) [18]. The response rates at 24 hours were $20.0 \%$ in the nitrous oxide group and $5.0 \%$ in the placebo group without any significance (Odds Ratio $(O R)=4.0,95 \% \mathrm{Cl}=0.5-35.8)$. The frequent adverse events included nausea/vomiting (15.0\%), head- 
- Table 1 Novel antidepressant in the pipeline.

\begin{tabular}{|c|c|c|c|c|}
\hline Compound & $\begin{array}{l}\text { Presumed } \\
\text { mechanism of } \\
\text { antidepressant } \\
\text { action }\end{array}$ & Phase & Sponsor & Characteristics \\
\hline AXS-05 & NMDAR antagonism & III & Axsome & $\begin{array}{l}\text { AXS-05 showed rapid and durable improvement in the MADRS total score } \\
\text { compared to placebo in one phase III DBRCT (NCT04019704). Another phase III } \\
\text { DBRCT demonstrated its rapid antidepressant effects in the MADRS total score } \\
\text { compared to bupropion (NCT02741791). One phase III open-label safety study has } \\
\text { just been completed without any reported results (NCT04039022). One phase II } \\
\text { trial is still in the recruitment stage on ClinicalTrials.gov (NCT04634669). }\end{array}$ \\
\hline MIJ821 (CAD9271) & $\begin{array}{l}\text { NMDAR subtype } 2 \mathrm{~B} \\
\text { negative allosteric } \\
\text { modulation }\end{array}$ & II & Novartis & $\begin{array}{l}\text { MIJ821 demonstrated greater improvements than placebo in the MADRS total } \\
\text { score at } 24 \text { hours in a phase II DBRCT (NCT03756129). One phase II DBRCT is } \\
\text { ongoing (NCT03756129). }\end{array}$ \\
\hline Nitrous oxide & NMDAR antagonism & II & None & $\begin{array}{l}\text { In a phase II crossover DBRCT, } 50 \% \text { nitrous oxide plus } 50 \% \text { oxygen was superior to } \\
\text { that of placebo gas in the improvement of the HAMD } \mathrm{HA}_{21} \text { at } 2 \mathrm{~h} \text { and } 24 \mathrm{~h} \\
\text { (NCT02139540). The results of other phase II studies examining } 25 \% \text { and } 50 \% \\
\text { nitrous oxide have not been reported yet (NCT03283670, NCT03932825). There is } \\
\text { one ongoing phase II DBRCT (NCT03869736). }\end{array}$ \\
\hline Psilocybin & $\begin{array}{l}\text { 5-hydroxytryptamine } \\
2 \text { A agonism }\end{array}$ & II & None & $\begin{array}{l}\text { One phase II waiting list-controlled trial demonstrated that the HAMD }{ }_{17} \text { scores } \\
\text { after two psilocybin sessions in the psilocybin group were significantly lower than } \\
\text { those in the waiting-list group (NCT03181529). In another phase II DBRCT, two } \\
\text { administrations of psilocybin were not inferior to the treatment of escitalopram in } \\
\text { the QIDS-SR } 16 \text { (NCT03429075). Some phase-II DBRCTs are ongoing } \\
\text { (NCT03775200, NCT03866174, NCT03715127). }\end{array}$ \\
\hline Ayahuasca & $\begin{array}{l}\text { 5-hydroxytryptamine } \\
2 \mathrm{~A} \text { agonism and } \\
\text { Monoamine oxidase } \\
\text { inhibition }\end{array}$ & II & None & $\begin{array}{l}\text { Rapid antidepressant effects in the HAMD total score were observed in ayahuasca } \\
\text { compared to placebo in one phase-II DBRCT (NCT02914769). No ongoing trial was } \\
\text { registered on ClinicalTrials.gov. }\end{array}$ \\
\hline $\begin{array}{l}\text { Botulinum toxin A } \\
\text { (BTA) }\end{array}$ & $\begin{array}{l}\text { Positive effects of } \\
\text { altered facial } \\
\text { expression on } \\
\text { emotional perception }\end{array}$ & II & None & $\begin{array}{l}\text { In a phase II crossover DBRCT, there was a significant improvement in the } \mathrm{HAMD}_{21} \\
\text { in the patients who received BTA compared with those who received placebo } \\
\text { (NCT01392963). In another phase II DBRCT, BTA showed a significant score } \\
\text { reduction in the MADRS compared to placebo (NCT02116361). The addition of } \\
\text { BTA to an ongoing antidepressant also demonstrated greater efficacy in the } \\
\text { HAMD }{ }_{17} \text { score reduction over placebo in a phase II DBRCT. In a phase IV DBRCT, } \\
\text { BTA showed a greater response rate on the MADRS compared to placebo } \\
\text { (NCT01556971). One clinical trial comparing two facial injection sites is ongoing } \\
\text { (NCT03484754). }\end{array}$ \\
\hline $\begin{array}{l}\text { Prasterone } \\
\text { (dehydroepiandro- } \\
\text { sterone, DHEA) }\end{array}$ & $\begin{array}{l}\text { Sigma receptor } \\
\text { agonism }\end{array}$ & II & None & $\begin{array}{l}\text { In one phase II crossover DBRCT, the administration of DHEA resulted in a } \\
\text { significant improvement in the HAMD }{ }_{17} \text { compared with placebo (NCT00001487). } \\
\text { No ongoing trial was registered on ClinicalTrials.gov. }\end{array}$ \\
\hline $\begin{array}{l}\text { Casopitant } \\
\text { (GW679769) }\end{array}$ & $\begin{array}{l}\text { NK receptor } \\
\text { antagonism }\end{array}$ & II & $\begin{array}{l}\text { GlaxoS- } \\
\text { mithKline }\end{array}$ & $\begin{array}{l}\text { In one phase II DBRCT, there was a significant difference in the HAMD } 17 \text { score } \\
\text { change between casopitant and placebo (NCT00413023). Another phase II DBRCT } \\
\text { reported that neither casopitant nor paroxetine achieved statistical separation } \\
\text { from placebo on the HAMD } \text { H }_{17} \text { (NCT00102492). No active trial was registered on } \\
\text { ClinicalTrials.gov. }\end{array}$ \\
\hline $\begin{array}{l}\text { Ansofaxine } \\
\text { hydrochloride } \\
\text { (LY03005, } \\
\text { LPM570065) }\end{array}$ & $\begin{array}{l}\text { Serotonin-norepi- } \\
\text { nephrine-dopamine } \\
\text { triple reuptake } \\
\text { inhibition }\end{array}$ & III & Luye & $\begin{array}{l}\text { Ansofaxine hydrochloride showed an antidepressant effect in the MADRS total } \\
\text { score compared to placebo in a recent phase III DBRCT (NCT04853407). No } \\
\text { ongoing trial was registered on ClinicalTrials.gov. }\end{array}$ \\
\hline
\end{tabular}

Abbreviations: DBRCT, double-blind, randomized controlled trial; HAMD, Hamilton Depression Rating Scale; MADRS, Montgomery-Asberg Depression Rating Scale; MDD major depressive disorder; NMDAR, N-methyl-D-aspartate receptor; QIDS-SR ${ }_{16}$, 16 -item Quick Inventory of Depressive Symptomatology, Self-Report; TRD, treatment-resistant depression.

ache (10.0\%), numbness/paresthesia (10.0\%), and anxiety (10.0\%). In another phase II crossover DBRCT of 24 patients with TRD, a single 1 -hour inhalation of $50 \%$ and $25 \%$ nitrous oxide in oxygen did not demonstrate significant reduction in the $\mathrm{HAMD}_{21}$ total score compared to placebo gas at hours 2, 24 and week 1, but did at week 2 (primary outcome, the estimated differences between $25 \% \mathrm{ni}$ trous oxide and placebo: -0.75 at 2 hours $(p=0.73),-1.41$ at 24 hours $(p=0.52),-4.35$ at week $1(p=0.05)$, and -5.19 at week $2(p=0.02)$; the estimated differences between $50 \%$ nitrous oxide and placebo: -0.87 at 2 hours $(p=0.69),-1.93$ at 24 hours $(p=0.37),-2.44$ at week $1(p=0.25)$, and -7.00 at week 2 $(p=0.001)$ (NCT03283670) [19]. The response rates at 2 weeks were $41.7 \%$ in the $50 \%$ nitrous oxide group (Relative Risk $(R R)=2.9$; $95 \% \mathrm{Cl}=0.6-18.0), 33.3 \%$ in the $25 \%$ nitrous oxide group $(R R=2.5$; $95 \% \mathrm{Cl}=0.4-16.3)$, and $11.1 \%$ in the placebo group. The most fre- 
- Table 2 Antidepressant drugs in the pipeline that failed to show any significant benefit over placebo in phase II and III trials.

\begin{tabular}{|c|c|c|c|}
\hline Compound & Phase & Patients & Characteristics \\
\hline AZD2327 & II & MDD & $\begin{array}{l}\text { No significant antidepressant effect was found in the HAMD } 17 \text { total score in AZD2327 compared with placebo } \\
\text { in a phase II DBRCT for MDD (NCT00759395). }\end{array}$ \\
\hline AZD7268 & II & MDD & $\begin{array}{l}\text { No significant difference was demonstrated in the MADRS total score between AZD7268 and placebo in a } \\
\text { phase II DBRCT for MDD (NCT01020799). }\end{array}$ \\
\hline $\begin{array}{l}\text { Decoglurant } \\
\text { (RG1578, } \\
\text { RO4995819) }\end{array}$ & II & MDD & $\begin{array}{l}\text { In a phase II DBRCT for MDD, no significant differences were observed between decoglurant and placebo in } \\
\text { the reduction in the MADRS total score and response and remission rates (NCT01457677). }\end{array}$ \\
\hline GSK163090 & II & MDD & $\begin{array}{l}\text { In a phase II DBRCT for MDD, GSK163090 showed no significant difference in the } \mathrm{HAMD}_{17} \text { total score } \\
\text { compared with placebo (NCT00896363). }\end{array}$ \\
\hline GSK372475 & II & MDD & $\begin{array}{l}\text { No significant difference was found in the MADRS total score between GSK372475 and placebo in two phase } \\
\text { II DBRCT for MDD (NCT00420641 and NCT00448058). }\end{array}$ \\
\hline GSK561679 & II & MDD & $\begin{array}{l}\text { GSK561679 did not show any significant difference in the HAMD }{ }_{17} \text { total score compared with placebo in a } \\
\text { phase II DBRCT for MDD (NCT00733980). }\end{array}$ \\
\hline GW856553 & II & MDD & $\begin{array}{l}\text { No significant difference was found in the HAMD } 17 \text { total score between GW856553 and placebo in a phase II } \\
\text { DBRCT for MDD (NCT00976560). }\end{array}$ \\
\hline JNJ-18038683 & $\|$ & MDD & $\begin{array}{l}\text { JNJ-18038683 demonstrated no statistically significant improvement over placebo in the MADRS total score in } \\
\text { a phase II DBRCT for MDD (NCT00566202). }\end{array}$ \\
\hline $\begin{array}{l}\text { Lanicemine } \\
\text { (AZD6765) }\end{array}$ & II & MDD & $\begin{array}{l}\text { In a phase II DBRCT for MDD, lanicemine showed a significantly greater reduction in the MADRS total score } \\
\text { within } 80 \text { minutes compared to placebo. However, the significant improvement remained only for } 110 \text { min- } \\
\text { utes (NCT00986479). The development of lanicemine was terminated in } 2013 \text {. }\end{array}$ \\
\hline $\begin{array}{l}\text { Mecamylamine } \\
\text { (TC-5214) }\end{array}$ & II & MDD & $\begin{array}{l}\text { There was no statistically significant difference in terms of total score reduction in the MADRS between } \\
\text { mecamylamine }(2 \mathrm{mg} / \mathrm{d} \text { or } 8 \mathrm{mg} / \mathrm{d}) \text { and placebo in a phase II DBRCT for MDD (NCT01288079). }\end{array}$ \\
\hline MIN-117 & II & MDD & $\begin{array}{l}\text { In a phase II DBRCT for MDD, no statistically significant difference was found between MIN-117 and placebo in } \\
\text { terms of total score reduction in the MADRS (NCT03446846). }\end{array}$ \\
\hline NSI-189 & II & MDD & $\begin{array}{l}\text { There was no statistically significant difference in total score reduction in the MADRS between NSI-189 } \\
(40 \mathrm{mg} / \mathrm{d} \text { or } 80 \mathrm{mg} / \mathrm{d}) \text { and placebo in a phase II DBRCT for MDD (NCT02695472). }\end{array}$ \\
\hline PDC-1421 & II & MDD & $\begin{array}{l}\text { In a phase II DBRCT for MDD, there was no statistically significant difference in terms of total score reduction } \\
\text { in the MADRS between PDC-1421 and placebo (NCT02395978). }\end{array}$ \\
\hline $\begin{array}{l}\text { Serdaxin (Zoraxel, } \\
\text { RX-10100) }\end{array}$ & II & MDD & $\begin{array}{l}\text { While several ad-hoc analyses showed non-significant but a trend-level greater percent change in the MADRS } \\
\text { total score in those treated with serdaxin compared to placebo, serdaxin did not demonstrate a pre-defined } \\
\text { superiority to placebo in a phase II DBRCT for MDD (NCT00839176). }\end{array}$ \\
\hline $\begin{array}{l}\text { Traxoprodil } \\
(\text { CP-101,606) }\end{array}$ & II & MDD & $\begin{array}{l}\text { Traxoprodil demonstrated a greater decrease in the MADRS total score compared with placebo in a phase II } \\
\text { DBRCT for MDD (NCT00163059). However, further development was not pursued due to a concern about } \\
\text { potential cardiovascular risk via QT prolongation. }\end{array}$ \\
\hline $\begin{array}{l}\text { Yohimbine } \\
\text { hydrochloride }\end{array}$ & II & MDD & $\begin{array}{l}\text { In a phase II crossover DBRCT for MDD, there was no significant difference in the } \mathrm{HAMD}_{6} \text { total score between } \\
\text { Yohimbine hydrochloride and placebo (NCT00078715). }\end{array}$ \\
\hline $\begin{array}{l}\text { Amibegron } \\
\text { (SR58611A) }\end{array}$ & III & MDD & $\begin{array}{l}\text { In a phase III DBRCT for MDD, amibegron was associated with a significantly greater decrease in the HAMD } \mathrm{HA}_{17} \\
\text { total score compared with placebo (NCT00825058). The development of amibegron was terminated in } 2008 \text {. }\end{array}$ \\
\hline $\begin{array}{l}\text { Aprepitant } \\
\text { (MK0869) }\end{array}$ & III & MDD & $\begin{array}{l}\text { No significant difference was found in the } \mathrm{HAMD}_{17} \text { total score change between aprepitant and placebo in a } \\
\text { phase III DBRCT for MDD (NCT00042029). }\end{array}$ \\
\hline Buprenorphine & III & TRD & $\begin{array}{l}\text { Low-dose buprenorphine provided a rapid and sustained improvement for older adults with TRD in a phase II } \\
\text { RCT. However, no significant difference was observed in the MADRS total score between buprenorphine and } \\
\text { placebo in a phase III DBRCT for TRD (NCT01407575). }\end{array}$ \\
\hline $\begin{array}{l}\text { Edivoxetine } \\
\text { (LY2216684) }\end{array}$ & III & MDD & $\begin{array}{l}\text { In a phase III DBRCT for MDD, edivoxetine demonstrated a significant total score reduction in the MADRS } \\
\text { compared with placebo (NCT00795821). However, edivoxetine did not separate from placebo in the MADRS } \\
\text { total core reduction in three acute phase III DBRCTs (NCT01185340, NCT01173601, NCT01187407). }\end{array}$ \\
\hline EPA & III & MDD & $\begin{array}{l}\text { No significant difference was observed in the HAMD }{ }_{17} \text { total score reduction between EPA and placebo in a } \\
\text { phase III DBRCT for MDD (NCT00361374). }\end{array}$ \\
\hline Ethyl-EPA & III & MDD & $\begin{array}{l}\text { Ethyl-EPA demonstrated a greater score reduction in the HAMD }{ }_{17} \text { total score compared with placebo; } \\
\text { however, it did not reach statistical significance in a phase III DBRCT for MDD (NCT00096798). }\end{array}$ \\
\hline Herbal extract & III & MDD & $\begin{array}{l}\text { No significant difference in the HAMD } 17 \text { total score was observed between herbal extract and placebo in a } \\
\text { phase III DBRCT for MDD (NCT01098318). }\end{array}$ \\
\hline $\begin{array}{l}\text { Rapastinel } \\
(\text { GLYX-13, BV-102) }\end{array}$ & III & TRD & $\begin{array}{l}\text { Rapastinel showed no greater improvement in the MADRS total score over placebo in a phase III DBRCT for } \\
\text { TRD and its development was discontinued (NCT03560518). }\end{array}$ \\
\hline $\begin{array}{l}\text { Zuranolone } \\
\text { (SAGE-217) }\end{array}$ & III & MDD & $\begin{array}{l}\text { In a phase III DBRCT for MDD, zuranolone did not show any statistically significant reduction from baseline } \\
\text { compared to placebo in the } \mathrm{HAMD}_{17} \text { total score (NCT03672175). }\end{array}$ \\
\hline
\end{tabular}


quently reported adverse event which occurred 24 hours after inhalation was common cold/strep throat (11.1\%). Mild dissociative effects were reported during or immediately after inhalation session in some patients who were receiving nitrous oxide (feeling disconnected, $26.1 \%$ in the $50 \%$ nitrous oxide group; lightheadedness, $8.7 \%$ and $5.0 \%$ in the $50 \%$ and $25 \%$ nitrous oxide groups, respectively; feeling high, $13.0 \%$ in the $50 \%$ nitrous oxide group; and paranoia, $4.3 \%$ in the $50 \%$ nitrous oxide group). The result of another phase II study examining 1 -hour inhalation of $50 \%$ nitrous oxide has not been reported, probably because it was only recently completed (NCT03932825). One phase II DBRCT is ongoing in which the participants have been randomized to receive 1-hour inhalation of $50 \%$ nitrous oxide, $25 \%$ nitrous oxide, or placebo gas (NCT03869736).

\section{Psilocybin}

Psilocybin is a psychedelic through serotonin 5-hydroxytryptamine type $2 \mathrm{~A}\left(5-\mathrm{HT}_{2 \mathrm{~A}}\right)$ receptor agonist, which occurs naturally in the psychoactive psilocybe genus of mushrooms [20]. One phase II waiting list-controlled trial of 27 patients with MDD demonstrated that the $\mathrm{HAMD}_{17}$ scores 1 (primary endpoint) and 4 weeks after two psilocybin sessions (session 1: $20 \mathrm{mg} / 70 \mathrm{~kg}$; session 2: $30 \mathrm{mg} / 70 \mathrm{~kg})$ in the psilocybin group $(8.0 \pm 7.1$ and $8.5 \pm 5.7$, respectively) were significantly lower than those in the waiting-list group (23.8 \pm 5.4 and $23.5 \pm 6.0$, respectively, both $p$-values <0.001) (NCT03181529) [20]. The response rates in the psilocybin group were $70.8 \%$ both at 1 and 4 weeks while data were not shown for the wait-list group. The adverse events in the psilocybin group included various emotional (e. g., fear and sadness) and physical (e. g., feeling body shake or tremble) experiences during psilocybin sessions, and headache. In another phase II DBRCT of 59 patients with MDD, two administrations of psilocybin ( $25 \mathrm{mg}$ of psilocybin 3 weeks apart plus 6 weeks of daily placebo) were not inferior to the 6-week treatment of escitalopram ( $1 \mathrm{mg}$ of psilocybin three weeks apart plus 10-20 mg escitalopram for 6 weeks) in the QIDS-SR 16 score changes (primary outcome, $-8.0 \pm 1.0$ and $-6.0 \pm 1.0$, respectively, $p=0.17$ ) (NCT03429075) [21]. The response rates at 6 weeks were $70.0 \%$ in the psilocybin group and $48.3 \%$ in the escitalopram group (difference: $22 \%, 95 \% \mathrm{Cl}:-3$ to 48). The common adverse events were headache (66.7\%), nausea (26.7\%), and migraine (10.0\%) in psilocybin. There was no report on dissociative symptoms, psychotic symptoms, or dependence. Other phase II DBRCTs targeting MDD are ongoing (NCT03775200, NCT03866174, and NCT03715127). Psilocybin received breakthrough therapy designation for the treatment of MDD in 2019.

\section{Ayahuasca}

Ayahuasca is a hallucinogenic botanical mixture that is traditionally used for healing and spiritual purposes in South America. Ayahuasca combines N, N-dimethyltryptamine (DMT), a psychedelic agent with 5-hydroxytryptamine $2 \mathrm{~A}$ agonist activity, with monoamine oxidase-inhibiting $\beta$-carboline alkaloids, such as harmine, harmaline, and tetrahydroharmine [22]. A single dose of ayahuasca ( $1 \mathrm{~mL} / \mathrm{kg}$ adjusted to contain $0.36 \mathrm{mg} / \mathrm{kg}$ of $\mathrm{N}, \mathrm{N}$-DMT) demonstrated a significant improvement in the HAMD total score of 14.4 compared to 2.8 for placebo on day 7 in one phase II DBRCT of 29 patients with TRD (primary outcome, $p=0.019$, Cohen's $d=1.49$ )
(NCT02914769) [23]. The response rates at day 7 between the ayahuasca and placebo groups were significantly different ( $57.1 \%$ versus $20.0 \%, \mathrm{OR}=5.3,95 \% \mathrm{Cl}=1.1-22.6, \mathrm{p}=0.04)$. In this study, most participants reported nausea and about $57 \%$ of them vomited. There were no data reported concerning other adverse events. No ongoing trial was registered on ClinicalTrials.gov as of August 22, 2021.

\section{Botulinum toxin A}

Local injections of botulinum toxin A (BTA; onabotulinumtoxinA) lead to muscle relaxation through a multistep mechanism [24]. BTA injections into the facial muscles in the glabellar region have been thought to have an antidepressant effect, possibly because facial expression influences emotional perception [25]. In a phase II crossover DBRCT of 30 patients with MDD, females received 29 units of BTA, and males received 39 units. In this study, there was a significant improvement in the $\mathrm{HAMD}_{21}$ in the patients who received BTA compared with those who received placebo at week 6 (primary outcome, -12.7 versus $-0.4, p<0.0001$ ) (NCT01392963) [25]. The response rate at week 6 was significantly higher in the BTA group than in the placebo group ( $55.6 \%$ versus $0.0 \%, p<0.0001$ ). There were no safety data reported in this study. In another phase II DBRCT for 255 female patients with MDD, 30 units of BTA, but not 50 units, showed a marginally significant score reduction in the MADRS compared to placebo at week 6 (primary endpoint, least-squares mean \pm standard error: $-11.6 \pm 1.4$ versus $-7.9 \pm 1.4, p=0.053$ ) (NCT02116361) [24]. Significant difference was also found at week $3(-7.8 \pm 1.1$ versus $-3.6 \pm 1.1, p=0.005)$ and $9(-13.7 \pm 1.3$ versus $-10.0 \pm 1.4, p=0.049)$ in this study. There was no available information on the response rate in this study. While headache commonly occurred in the BTA group (15.4\%), there was no report on dissociative symptoms, psychotic symptoms, or dependence. The addition of BTA (29 units for females and 39 units for males) to an ongoing antidepressant also demonstrated greater efficacy in the $\mathrm{HAMD}_{17}$ score reduction over placebo at week 6 in a phase II DBRCT of 30 patients with MDD (primary outcome, $-10.1 \pm 8.2$ versus $-1.7 \pm 4.3, p=0.002$ ) (NCT00934687) [26]. The response rate at week 6 was significantly higher in the additional BTA group than in the additional placebo group $(60.0 \%$ versus $13.3 \%, p=0.02)$. Short episodes of headache were the only relevant adverse event $(40.0 \%$ in the additional BTA group). In a phase IV DBRCT of 85 patients with MDD, BTA (29 units for females and 40 units for males) showed a greater rate of response compared to placebo at week 6 (primary outcome, $51.5 \%$ versus $14.6 \%, p<0.001$ ) (NCT01556971) [27]. Safety data were not shown in this study. One clinical trial comparing two facial injection sites (i. e., in the corrugator and procerus and the lateral muscle orbicularis oculi) is ongoing (NCT03484754).

\section{Prasterone}

Prasterone (dehydroepiandrosterone, DHEA) is a steroid hormone precursor used to treat painful sexual intercourse due to vaginal atrophy. In one phase II crossover DBRCT of 46 participants with midlife-onset major or minor depression, the 6-week administration of DHEA ( $90 \mathrm{mg} / \mathrm{d}$ for 3 weeks and $450 \mathrm{mg} / \mathrm{d}$ for 3 weeks) resulted in a significant improvement in the $\mathrm{HAMD}_{17}$ compared with the 6-week treatment with placebo (primary outcome, $13.3 \pm 0.9$ to $7.5 \pm 1.2$ versus $13.5 \pm 0.8$ to $11.8 \pm 1.1, \mathrm{p}<0.01$ ) (NCT00001487) 
[28]. While $50.0 \%$ of the participants responded after the DHEA treatment, $28.3 \%$ responded after receiving a placebo $(p=0.03)$. None reported adverse events in this study, except for one patient who experienced an increase in the skin oiliness. No ongoing trial was registered on ClinicalTrials.gov as of August 22, 2021.

\section{Casopitant}

Casopitant (GW679769) is an antagonist of the neurokinin (NK) receptor that is located in areas of the brain related to the regulation of affect and stress behaviors, including the amygdala hypothalamus, hippocampus, frontal cortex, raphe nucleus, and locus coeruleus [29]. In one phase II DBRCT of 356 patients with MDD, there was a significant difference in the $\mathrm{HAMD}_{17}$ score change at week 8 (primary outcome) between casopitant $80 \mathrm{mg} / \mathrm{d}$ and placebo (difference $=-2.7, p=0.023$ ), but not between casopitant $30 \mathrm{mg} / \mathrm{d}$ and placebo (difference $=-2.1, \mathrm{p}=0.077)($ NCT00413023) [29]. A significant difference between casopitant $80 \mathrm{mg} / \mathrm{d}$ and placebo was detected at week $1(p=0.010)$. The response rates at week 8 in the casopitant groups ( $40 \%$ in the $80 \mathrm{mg} / \mathrm{d}$ group and $39 \%$ in the $30 \mathrm{mg} / \mathrm{d}$ group) were not significantly different from that in the placebo group ( $32 \%$, both p's $>0.05)$. Another phase II DBRCT of 362 patients with MDD reported that neither casopitant $80-120 \mathrm{mg} / \mathrm{d}$ nor paroxetine $30 \mathrm{mg} / \mathrm{d}$ achieved statistical separation from placebo at week 8 on the $\mathrm{HAMD}_{17}$ (primary outcome, difference for casopitant $=-1.7, p=0.114$ and difference for paroxetine $=-1.2, p=0.282)($ NCT00102492) [29]. The response rate at week 8 in neither the casopitant group (62\%) nor the paroxetine group (60\%) was not different from that in the placebo group $(59 \%$, both p's $>0.05$ ). The adverse events that occurred $\geq 10 \%$ in one or more casopitant groups in these two studies included headache, somnolence, nausea, diarrhea, and dry mouth. There was no report of dissociative symptoms, psychotic symptoms, or dependence. No active trial was registered on ClinicalTrials.gov.

\section{Ansofaxine hydrochloride}

Ansofaxine hydrochloride (LY03005, LPM570065) is a prodrug of desvenlafaxine which works as a serotonin-norepinephrine-dopamine reuptake inhibitor [30]. In a recent phase III DBRCT of 558 patients with MDD, the 8-week administration of ansofaxine hydrochloride $(80 \mathrm{mg} / \mathrm{d}$ or $160 \mathrm{mg} / \mathrm{d})$ resulted in a significant improvement in the MADRS compared with placebo although the detailed information was not reported (NCT04853407) [31,32]. The common adverse events were nausea, vomiting, headache, and drowsiness. No active trial was registered on ClinicalTrials.gov as of August 22, 2021.

\section{Discussion}

The latest report of a systematic search of not-yet-marketed antidepressant compounds showed positive results in phase II and III trials. The search in the US Clinical Trials registry identified nine compounds. AXS-05 provided a positive result over placebo in one phase III DBRCT for TRD and immediate antidepressant effect over bupropion in another phase III DBRCT for TRD. As TRD was targeted in these studies, AXS-05 may be considered to be a promising treatment option for those who did not respond to conventional antidepressants. Eight other compounds, including MIJ821, nitrous oxide, psilocybin, ayahuasca, facial injection of BTA, prasterone, casopitant, and ansofaxine hydrochloride demonstrated at least one positive result in phase II or III trials for TRD or MDD. Six compounds demonstrated the significant score reduction in the rating scale used for each primary outcome compared with placebo within one week (i. e., nitrous oxide, a few hours; MIJ821 and ayahuasca, one day; AXS-05, psilocybin, and casopitant, one week); of these, ayahuasca showed a greater response rate than placebo within one week. These new compounds with novel mechanisms of action beyond the conventional monoaminergic hypothesis are expected to provide a greater variety of treatment options in pharmacotherapy for depression in the near future if these preliminary results are confirmed.

AXS-05, MIJ821, and nitrous oxide have antagonistic or negative allosteric activity modulation in NMDAR like ketamine. The antidepressant effects of several NMDAR modulators have been examined since discovering the antidepressant effects of ketamine in 2000 [33]. However, other than these three drugs, NMDAR modulators generally failed to show superiority to placebo (e. g., rapastinel [GLYX-13] [34] and L-4-chlorokynurenine [AV-101] [35]), and the development of lanicemine (AZD6765, BHV-5000) seemed to be terminated [36]. The following mechanisms have been thought to underlie the antidepressant effects of ketamine: (1) inhibition of NMDARs localized to GABA inhibitory interneurons, (2) a cascade of intracellular changes due to transient inhibition of postsynaptic NMDAR activity, (3) activation of cellular plasticity cascades from inhibition of extrasynaptic NMDARs, and (4) inhibition of NMDARdependent high-frequency burst firing in the lateral habenula [37]. However, the antidepressant effects of ketamine are recently considered to be independent of NMDAR inhibition because of its more significant antidepressant-like effect and less potent inhibition of NMDAR in (R)-ketamine than (S)-ketamine [38]. Moreover, an NMDAR antagonist, MK-801, which binds to the same receptor site as ketamine, does not exert sustained antidepressant effects [39]. Instead, the antidepressant effects of ketamine require the acute activation of AMPAR. A single subanesthetic dose of ketamine produces a rapid increase in the expression levels of the AMPAR GluA1 subunit in the medial prefrontal cortex in a rodent model [40]. In addition, pretreatment with an AMPAR antagonist blocks the antidepressant-like behavioral effects of ketamine [41]. Altogether, these findings indicate that AMPARs likely play a pivotal role in the antidepressant actions of ketamine. As described above, AXS-05 is a combination of dextromethorphan and bupropion. Similar to ketamine, pretreatment with an AMPAR antagonist significantly blocks the antidepressant-like behavior of dextromethorphan, suggesting that AMPARs may also play a significant role in the antidepressant-like effects of dextromethorphan [42]. While the antidepressant effects of nitrous oxide and MIJ821 are unclear, the repeated exposure of nitrous oxide increases burst firing activity, which may lead to antidepressant-like effects [43].

Increasing evidence suggests the safety and efficacy of psychedelic compounds as potential novel therapeutics in psychiatry $[44,45]$. Some clinical trials have demonstrated the safety, efficacy, and tolerability of (1) 3,4-methylenedioxymethamphetamine and lysergic acid diethylamide (LSD) for treatment-resistant posttraumatic stress disorder [46-48]; (2) psilocybin for the obsessivecompulsive disorder [49], (3) alcohol abuse [50], (4) smoking cessation [51], and (5) psilocybin and LSD for anxiety, depression, pain, 
and distress associated with a life-threatening illness [52, 53]. As described in the present review, several clinical trials have shown the efficacy of psilocybin and ayahuasca for TRD. Most psychedelics, including psilocybin and ayahuasca, are $5-\mathrm{HT}_{2 \mathrm{~A}}$ receptor agonists, which are thought to mediate their psychedelic and hallucinogenic effects $[54,55]$. Psychedelic compounds may induce brain-derived neurotrophic factor-mediated AMPAR potentiation and enhancement of neural plasticity $[56,57]$, possibly resulting in antidepressant effects. Future studies are needed to dissect the mechanisms of these antidepressant effects in a compound- and dosage-specific manner [58].

The safety and efficacy of BTA, prasterone, casopitant, and ansofaxine hydrochloride have also been demonstrated for the treatment of MDD. Treatment of the glabellar region with botulinum toxin produces a relative change in the facial expressions, from negative to positive, possibly impacting emotional experience [26]. Prasterone stimulates neurogenesis and increases hippocampal spine synapse density in the rat hippocampus $[59,60]$, potentially leading to neuroprotective and proliferative effects. Casopitant increases serotonin and norepinephrine neurotransmitters through the NK1 receptor system [61]. Ansofaxine hydrochloride blocks serotonin, norepinephrine, and dopamine transporters [30].

This review has several limitations. First, only the US Clinical Trials registry was searched for relevant clinical trials and antidepressant compounds. However, this is the largest registry that contains more than 384,000 clinical trials, which is six times larger than the European registry. Second, the collection of collateral information via the PubMed search and press releases was not performed systematically. Third, the targeted populations (i. e., MDD or TRD), primary outcome measures (i. e., score reductions in the HAMD and MADRS and response rate), and primary endpoints (i. e., from 24 hours to 6 weeks) differed among individual studies. Those with TRD may be less likely to respond to treatment of interest compared to those with MDD since the lower response rate was observed in the later treatment step in the Sequenced Treatment Alternatives to Relieve Depression (STAR * D) trial [7]. Furthermore, the primary endpoint was not clarified in one study for nitrous oxide [19]. Fourth, the superiority/inferiority of each compound to ketamine cannot be examined because a direct comparison of only MIJ821 with ketamine is reported. Finally, it should be noted that the compounds demonstrated significant superiority to placebo in the primary outcome measure at the primary endpoint in the latest phase of clinical trials, regardless of their mechanisms of actions or presence/absence of rapid-acting property.

In conclusion, the present study identified nine promising antidepressant compounds (i. e., AXS-05, MIJ821, nitrous oxide, psilocybin, ayahuasca, facial injection of BTA, prasterone, casopitant, and ansofaxine hydrochloride) that demonstrated positive results in phase II or III studies for MDD or TRD. These new drugs with novel mechanisms of action can address unmet needs for the treatment of depression. At the same time, their efficacy and safety must be rigorously examined before they are marketed.

\section{Role of Funding}

This work was funded by Keio Next-Generation Research Project Program.

\section{Conflict of Interest}

Dr. Sakurai reports grants from the Uehara Memorial Foundation and manuscript fees or speaker's honoraria from Eisai, Meiji Seika Pharma, Shionogi Pharma, Sumitomo Dainippon Pharma, Takeda Pharma, and Yoshitomi Yakuhin. Dr. Yonezawa has nothing to declare. Dr. Tani received a fellowship from the Japanese Society of Clinical Neuropsychopharmacology and the Canadian Institutes of Health Research, a research grant from Eli Lilly, and manuscript fees from Dainippon Sumitomo Pharma, Otsuka Pharmaceutical, Wiley Japan, and Yoshitomi Yakuhin. Dr. Mimura has received speaker's honoraria from Byer Pharmaceutical, Daiichi Sankyo, Dainippon-Sumitomo Pharma, Eisai, Eli Lilly, Fuji Film RI Pharma, Hisamitsu Pharmaceutical, Janssen Pharmaceutical, Kyowa Pharmaceutical, Mochida Pharmaceutical, MSD, Mylan EPD, Nihon Medi-physics, Nippon Chemipher, Novartis Pharma, Ono Yakuhin, Otsuka Pharmaceutical, Pfizer, Santen Pharmaceutical, Shire Japan, Takeda Yakuhin, Tsumura, and Yoshitomi Yakuhin within the past three years. Also, he received grants from Daiichi Sankyo, Eisai, Pfizer, Shionogi, Takeda, Tanabe Mitsubishi, and Tsumura within the past three years outside the submitted work. Dr. Bauer has received institutional funding/grant support from Deutsche Forschungsgemeinschaft (DFG), Bundesministeriums für Bildung und Forschung (BMBF), and the European Commission. He has received speaker honoraria and/or travel compensation from Aristo, Hexal AG, Janssen Pharmaceutica NV, JanssenCilag, and Sunovion. He has served on advisory boards or honoraria for consultancy from GH Research, Janssen-Cilag, Neuraxpharm, Novartis, Sandoz, Shire International GmbH, Sumitomo Dainippon, Sunovion, and Takeda. Dr. Uchida has received grants from Eisai, Otsuka Pharmaceutical, Dainippon-Sumitomo Pharma, Daiichi Sankyo Company, Mochida Pharmaceutical, and Meiji-Seika Pharma; speaker's honoraria from Otsuka Pharmaceutical, Dainippon-Sumitomo Pharma, Eisai, and Meiji-Seika Pharma, and advisory panel payments from Dainippon-Sumitomo Pharma within the past 3 years.

References

[1] Park LT, Zarate CA. Depression in the primary care setting. N Engl J Med 2019; 380: 559-568

[2] American Psychiatric Association Practice guideline for the treatment of patients with major depressive disorder. 3rd ed. Washington, DC: APA; 2010

[3] Kennedy SH, Lam RW et al. Canadian network for mood and anxiety treatments (CANMAT) 2016 clinical guidelines for the management of adults with major depressive disorder: Section 3. Pharmacological Treatments. Can J Psychiatry Rev Can Psychiatr 2016; 61: 540-560

[4] Bauer M, Pfennig A, Severus E et al. World Federation of Societies of Biological Psychiatry (WFSBP) guidelines for biological treatment of unipolar depressive disorders, part 1: Update 2013 on the acute and continuation treatment of unipolar depressive disorders. World J Biol Psychiatry 2013; 14: 334-385 
[5] Stassen HH, Angst ], Hell D et al. Is there a common resilience mechanism underlying antidepressant drug response? Evidence from 2848 patients. J Clin Psychiatry 2007; 68: 1195-1205

[6] Gaynes BN, Warden D, Trivedi MH et al. What did STAR * D teach us? Results from a large-scale, practical, clinical trial for patients with depression. Psychiatr Serv Wash DC 2009; 60: 1439-1445

[7] Rush A], Trivedi MH, Wisniewski SR et al. Acute and longer-term outcomes in depressed outpatients requiring one or several treatment steps: a STAR * D report. Am J Psychiatry 2006; 163: 1905-1917

[8] Witkin JM, Martin AE, Golani LK et al. Rapid-acting antidepressants. Adv Pharmacol San Diego Calif 2019; 86: 47-96

[9] Wilkinson ST, Sanacora G. A new generation of antidepressants: An update on the pharmaceutical pipeline for novel and rapid-acting therapeutics in mood disorders based on glutamate/GABA neurotransmitter systems. Drug Discov Today 2019; 24: 606-615

[10] Gerhard DM, Duman RS. Rapid-acting antidepressants: Mechanistic insights and future directions. Curr Behav Neurosci Rep 2018; 5: 36-47

[11] Wilkinson ST, Sanacora G. Ketamine: A potential rapid-acting antisuicidal agent? Depress Anxiety 2016; 33: 711-717

[12] Wilkinson ST, Toprak M, Turner MS et al. A Survey of the clinical, off-label use of ketamine as a treatment for psychiatric disorders. Am J Psychiatry 2017; 174: 695-696

[13] Axsome Therapeutics Inc.Axsome Therapeutics Announces AXS-05 Achieves Primary Endpoint in GEMINI Phase 3 Trial in Major Depressive Disorder 2019; https://www.globenewswire.com/en/news-relea se/2019/12/16/1960786/33090/en/Axsome-Therapeutics-AnnouncesAXS-05-Achieves-Primary-Endpoint-in-GEMINI-Phase-3-Trial-in-MajorDepressive-Disorder.html

[14] Axsome Therapeutics Inc.Axsome Therapeutics Announces Topline Results of the STRIDE-1 Phase 3 Trial in Treatment Resistant Depression and Expert Call to Discuss Clinical Implications 2020; https://www.biospace.com/article/releases/axsome-therapeuticsannounces-topline-results-of-the-stride-1-phase-3-trial-in-treatmentresistant-depression-and-expert-call-to-discuss-clinical-implications/

[15] Axsome Therapeutics Inc.Axsome Therapeutics Announces AXS-05 Achieves Pprimary and Key Secondary Endpoints in the Merit Phase 2 Trial in Treatment Resistant Depression 2021; https://www. globenewswire.com/news-release/2021/08/09/2276951/33090/en/ Axsome-Therapeutics-Announces-AXS-05-Achieves-Primary-and-KeySecondary-Endpoints-in-the-MERIT-Phase-2-Trial-in-TreatmentResistant-Depression.html

[16] Proof of Concept Study Evaluating the Efficacy and Safety of MIJ821 in Patients With Treatment-resistant Depression 2021; https:// clinicaltrials.gov/ct2/show/NCT03756129

[17] Becker DE, Rosenberg M. Nitrous oxide and the inhalation anesthetics. Anesth Prog 2008; 55: 124-130

[18] Nagele P, Duma A, Kopec M et al. Nitrous oxide for treatment-resistant major depression: A proof-of-concept trial. Biol Psychiatry 2015; 78: $10-18$

[19] Nagele P, Palanca B], Gott B et al. A phase 2 trial of inhaled nitrous oxide for treatment-resistant major depression. Sci Transl Med 2021; 13: eabe1376

[20] Davis AK, Barrett FS, May DG et al. Effects of psilocybin-assisted therapy on major depressive disorder: A randomized clinical trial. JAMA Psychiatry 2021; 78: 481-489

[21] Carhart-Harris R, Giribaldi B, Watts R et al. Trial of psilocybin versus escitalopram for depression. N Engl J Med 2021; 384: 1402-1411

[22] Riba J, Valle M, Urbano G et al. Human pharmacology of ayahuasca: Subjective and cardiovascular effects, monoamine metabolite excretion, and pharmacokinetics. J Pharmacol Exp Ther 2003; 306: 73-83
[23] Palhano-Fontes F, Barreto D, Onias $\mathrm{H}$ et al. Rapid antidepressant effects of the psychedelic ayahuasca in treatment-resistant depression: A randomized placebo-controlled trial. Psychol Med 2019; 49: 655-663

[24] Brin MF, Durgam S, Lum A et al. OnabotulinumtoxinA for the treatment of major depressive disorder: A phase 2 randomized, double-blind, placebo-controlled trial in adult females. Int Clin Psychopharmacol 2020; 35: 19-28

[25] Magid M, Reichenberg JS, Poth PE et al. Treatment of major depressive disorder using botulinum toxin A: A 24-week randomized, doubleblind, placebo-controlled study. J Clin Psychiatry 2014; 75: 837-844

[26] Wollmer MA, de Boer C, Kalak $N$ et al. Facing depression with botulinum toxin: A randomized controlled trial. J Psychiatr Res 2012; 46: 574-581

[27] Finzi E, Rosenthal NE. Treatment of depression with onabotulinumtoxinA: A randomized, double-blind, placebo controlled trial. J Psychiatr Res 2014; 52: 1-6

[28] Schmidt P], Daly RC, Bloch M et al. Dehydroepiandrosterone monotherapy in midlife-onset major and minor depression. Arch Gen Psychiatry 2005; 62: 154-162

[29] Ratti E, Bellew K, Bettica P et al. Results from 2 randomized, double-blind, placebo-controlled studies of the novel NK1 receptor antagonist casopitant in patients with major depressive disorder. J Clin Psychopharmacol 2011; 31: 727-733

[30] Zhang R, Li X, Shi Y et al. The effects of LPM570065, a novel triple reuptake inhibitor, on extracellular serotonin, dopamine and norepinephrine levels in rats. PloS One 2014; 9: e91775

[31] Clinicaltrials.gov. A Study to Evaluate the Efficacy and Safety of Ansofaxine Hydrochloride Extended-release Tablets in the Treatment of Major Depressive Disorder (MDD). 2021; https://clinicaltrials.gov/ ct2/show/NCT04853407

[32] Luye Pharma Luye Pharma's Class 1 New Drug Anshufaxine Hydrochloride Extended-Release Tablets Meets Predefined Endpoints in Phase III Trial. 2021; https://www.luye.cn/lvye_en/view. php?id $=1922$

[33] Berman RM, Cappiello A, Anand A et al. Antidepressant effects of ketamine in depressed patients. Biol Psychiatry 2000; 47: 351-354

[34] Allergan Allergan Announces Phase 3 Results for Rapastinel as an Adjunctive Treatment of Major Depressive Disorder (MDD). 2019; https://www.prnewswire.com/news-releases/allergan-announcesphase-3-results-for-rapastinel-as-an-adjunctive-treatment-of-majordepressive-disorder-mdd-300808044.html

[35] VistaGen Therapeutics VistaGen Reports Topline Phase 2 Results for AV-101 as an Adjunctive Treatment of Major Depressive Disorder. 2019; https://www.vistagen.com/news-media/press-releases/ detail/130/vistagen-reports-topline-phase-2-results-for-av-101-as-an

[36] Carroll ]. AstraZeneca quietly sweeps out some notable mid-stage drug programs. 2014; https://www.fiercebiotech.com/r-d/ astrazeneca-quietly-sweeps-out-some-notable-mid-stage-drugprograms

[37] Gould TD, Zarate CA, Thompson SM. Molecular pharmacology and neurobiology of rapid-acting antidepressants. Annu Rev Pharmacol Toxicol 2019; 59: 213-236

[38] Yang C, Shirayama Y, Zhang JC et al. R-ketamine: A rapid-onset and sustained antidepressant without psychotomimetic side effects. Transl Psychiatry 2015; 5: e632

[39] Zanos P, Moaddel R, Morris PJ et al. NMDAR inhibition-independent antidepressant actions of ketamine metabolites. Nature 2016; 533: 481-486

[40] Li N, Lee B, Liu R-J et al. mTOR-dependent synapse formation underlies the rapid antidepressant effects of NMDA antagonists. Science 2010; 329: 959-964 
[41] Maeng S, Zarate CA, Du J et al. Cellular mechanisms underlying the antidepressant effects of ketamine: role of alpha-amino-3-hydroxy-5methylisoxazole-4-propionic acid receptors. Biol Psychiatry 2008; 63: 349-352

[42] Nguyen L, Matsumoto RR. Involvement of AMPA receptors in the antidepressant-like effects of dextromethorphan in mice. Behav Brain Res 2015; 295: 26-34

[43] Liu W, Li Q, Ye B, Cao H, Shen F, Xu Z, Du W, Guo F, Liu ], Li T, Zhang B, Liu Z. Repeated Nitrous Oxide Exposure Exerts Antidepressant-Like Effects Through Neuronal Nitric Oxide Synthase Activation in the Medial Prefrontal Cortex. Front Psychiatry. 2020 Sep 3; 11: 837. doi: 10.3389/fpsyt.2020.00837. PMID: 33088274; PMCID: PMC7495238

[44] Nichols DE, Walter $\mathrm{H}$. The history of psychedelics in psychiatry. Pharmacopsychiatry 2021; 54: 151-166

[45] Gründer G. Psychedelics: A new treatment paradigm in psychiatry? Pharmacopsychiatry 2021; 54: 149-150

[46] Mithoefer MC, Feduccia AA, Jerome L et al. MDMA-assisted psychotherapy for treatment of PTSD: Study design and rationale for phase 3 trials based on pooled analysis of six phase 2 randomized controlled trials. Psychopharmacology (Berl) 2019; 236: 2735-2745

[47] Mithoefer MC, Mithoefer AT, Feduccia AA et al. 3,4-methylenedioxymethamphetamine (MDMA)-assisted psychotherapy for post-traumatic stress disorder in military veterans, firefighters, and police officers: A randomised, double-blind, dose-response, phase 2 clinical trial. Lancet Psychiatry 2018; 5 : 486-497

[48] Schmid Y, Gasser P, Oehen P et al. Acute subjective effects in LSD- and MDMA-assisted psychotherapy. J Psychopharmacol 2021; 35: 362-374

[49] Moreno FA, Wiegand CB, Taitano EK et al. Safety, tolerability, and efficacy of psilocybin in 9 patients with obsessive-compulsive disorder. J Clin Psychiatry 2006; 67: 1735-1740

[50] Bogenschutz MP, Forcehimes AA, Pommy JA et al. Psilocybin-assisted treatment for alcohol dependence: a proof-of-concept study. J Psychopharmacol 2015; 29: 289-299
[51] Johnson MW, Garcia-Romeu A, Cosimano MP et al. Pilot study of the 5-HT2AR agonist psilocybin in the treatment of tobacco addiction. J Psychopharmacol 2014; 28: 983-992

[52] Gasser P, Holstein D, Michel Y et al. Safety and efficacy of lysergic acid diethylamide-assisted psychotherapy for anxiety associated with life-threatening diseases. J Nerv Ment Dis 2014; 202: 513-520

[53] Griffiths RR, Johnson MW, Carducci MA et al. Psilocybin produces substantial and sustained decreases in depression and anxiety in patients with life-threatening cancer: A randomized double-blind trial. J Psychopharmacol 2016; 30: 1181-1197

[54] Nichols DE. Psychedelics. Pharmacol Rev 2016; 68: 264-355

[55] Gründer G, Jungaberle $\mathrm{H}$. The potential role of psychedelic drugs in mental health care of the future. Pharmacopsychiatry 2021; 54 : 191-199

[56] Inserra A, De Gregorio D, Gobbi G. Psychedelics in psychiatry: Neuroplastic, immunomodulatory, and neurotransmitter mechanisms. Pharmacol Rev 2021; 73: 202-277

[57] Ly C, Greb AC, Cameron LP et al. Psychedelics promote structural and functional neural plasticity. Cell Rep 2018; 23: 3170-3182

[58] Mertens L], Preller KH. Classical psychedelics as therapeutics in psychiatry - current clinical evidence and potential therapeutic mechanisms in substance use and mood disorders. Pharmacopsychiatry 2021; 54: 176-190

[59] Karishma KK, Herbert J. Dehydroepiandrosterone (DHEA) stimulates neurogenesis in the hippocampus of the rat, promotes survival of newly formed neurons and prevents corticosterone-induced suppression. Eur J Neurosci 2002; 16: 445-453

[60] Hajszan T, MacLusky N], Leranth C. Dehydroepiandrosterone increases hippocampal spine synapse density in ovariectomized female rats. Endocrinology 2004; 145: 1042-1045

[61] Gobbi G, Blier P. Effect of neurokinin-1 receptor antagonists on serotoninergic, noradrenergic and hippocampal neurons: Comparison with antidepressant drugs. Peptides 2005; 26: 1383-1393 